\title{
Cloverleaf duodenum
}

\section{Robert D'Agostino}

Department of Radiology, The University of Vermont Medical Center, 111 Colchester Ave, Burlington, VT 05401, USA

Lewis Gregory Cole, M.D., first described this peculiar deformity of the duodenal bulb. He insisted that this conformation was characteristic of duodenal ulcer in the vast majority of cases, and periduodenal disease in some others. In 1922, it was hailed as a pathognomonic sign to a round of applause [1].

Because of the recurrent course of duodenal ulcer disease before the advent of $\mathrm{H}-2$ blockers and protonpump inhibitors, after several episodes of ulceration and healing, permanent strands of scar tissue constrict the lumen of the duodenal bulb limiting its normal distensibility [2]. The resultant bulging of the fornices creates "pseudodiverticula" along the duodenal bulb margins, forming the classic cloverleaf or trifoliate appearance seen during a fluoroscopic examination (Fig. 1).

Named after the plants of the genus Trifolium, most are familiar with the three leaf (Fig. 2), and the rare four leaf clover.

Although some maybe asymptomatic [3], patients with this deformity can present with symptoms of gastric outlet obstruction [4].

Correspondence to: Robert D'Agostino; email: Robert.D'Agostino@, uvmhealth.org

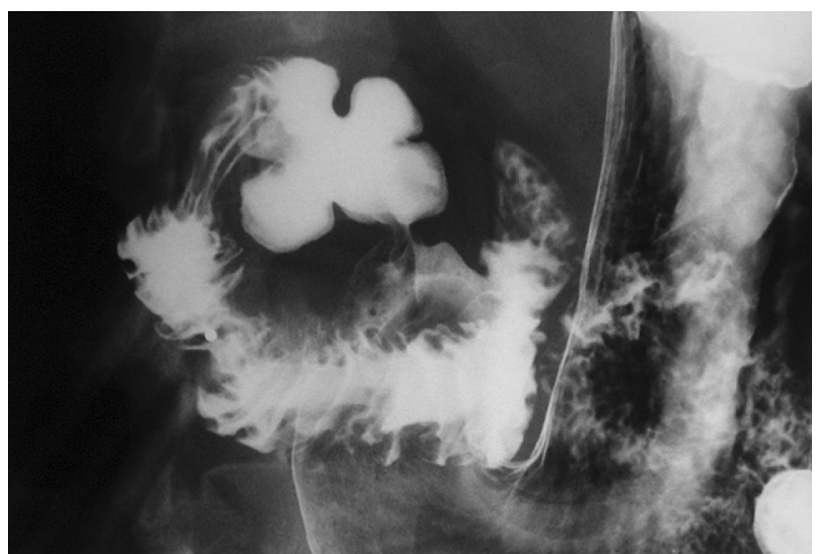

Fig. 1. Cloverleaf deformity of the duodenum on upper GI series.

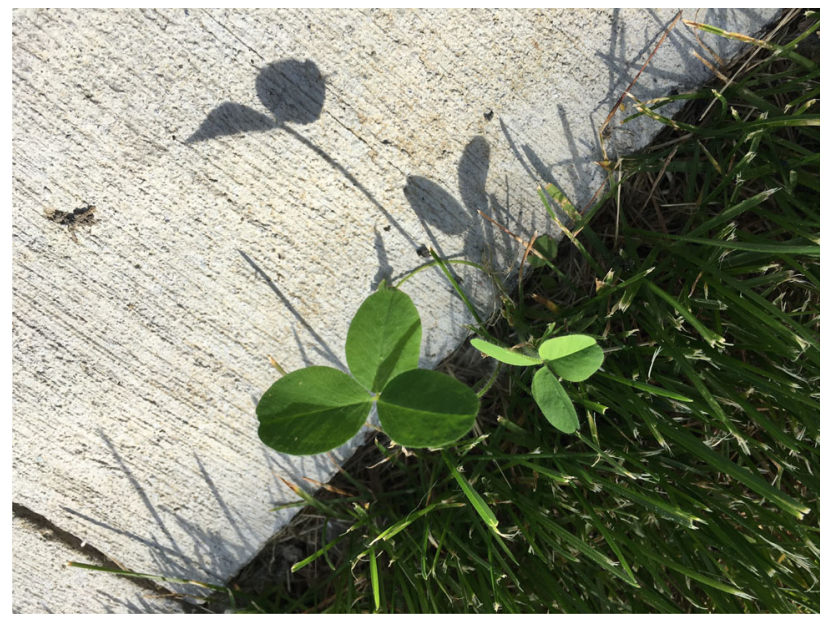

Fig. 2. Cloverleaf and shadow.

\section{References}

1. Carmen RD (1922) Errors in the roentogenologic diagnosis of duodenal ulcer. J Radiol 3(5):163-169

2. Novelline RA (2004) Squire's fundamentals of radiology, 6th edn. Boston: Harvard University Press

3. Bilbao MK, Frische LH, Rösch J, Benson JA Jr, Dotter CT (1971) Postbulbar duodenal ulcer and ring-stricture cause and effect. Radiology 100:27-35

4. Freeman AH, Sala E (2007) Radiology of the stomach and duodenum. Berlin: Springer 